\title{
Meropenem Efflux in Pseudomonas aeruginosa at a Tertiary Care Hospital in Jamaica

\author{
C Thoms-Rodriguez ${ }^{1}$, T Mazzulli' ${ }^{2,3}$, N Christian ${ }^{1}$, BM Willey $^{2}$, AM Nicholson $^{1}$
}

\begin{abstract}
Objective: Several mechanisms account for carbapenem resistance in Pseudomonas (P) aeruginosa which is an emerging problem at a tertiary care hospital (TCH) in Jamaica. The observed pattern of carbapenem resistance that results from efflux mechanisms is unique because it is specific to meropenem (MEM). An investigation of efflux as a mechanism of carbapenem resistance was needed as the information obtained could inform therapeutic and infection control strategies.

Methods: At the Microbiology Laboratory of a TCH in Jamaica, from May 2009 to March 2011, of 105 multidrug-resistant Gram-negative bacilli isolated from clinical specimens submitted for routine identification and susceptibility testing, all the MEM-resistant $\mathrm{P}$ aeruginosa isolates (a total of 10) were selected. They were tested for efflux using the efflux inhibitor phenylalanine-arginine- $\beta$-naphthylamide (PABN) in a method described by Giske et al in 2008. Results: This study detected evidence of MEM efflux in $80 \%$ of MEM-resistant $\mathrm{P}$ aeruginosa implicated in nosocomial infections at this TCH in Jamaica, using the PABN inhibition assay. Meropenem-efflux-positive isolates belonged to two unrelated chromosomal lineages.

Conclusion: These results underscored the need for improved surveillance and control to prevent this mechanism from emerging in further $\mathrm{P}$ aeruginosa strains.
\end{abstract}

Keywords: Efflux, Pseudomonas, resistance

\section{Eflujo de meropenem en Pseudomonas aeruginosa en un hospital de atención terciaria en Jamaica \\ C Thoms-Rodriguez ${ }^{1}$, T Mazzulli' ${ }^{2,3}, \mathrm{~N}_{\text {Christian }}{ }^{1}$, BM Willey ${ }^{2}$, AM Nicholson $^{1}$}

\begin{abstract}
RESUMEN
Objetivo: Varios mecanismos explican la resistencia al carbapenem en Pseudomonas (P) Aeruginosa - un problema que recientemente se está presentando en un hospital de atención terciaria (HAT) en Jamaica. El patrón observado de resistencia al carbapenem que resulta de los mecanismos de eflujo es único, porque es especifico del meropenem (MEM). Fue necesario realizar una investigación del eflujo como mecanismo de resistencia al carbapenem, ya que la información obtenida podría usarse para las estrategias de terapia y de control de la infección.
\end{abstract}

From: 'Department of Microbiology, The University of the West Indies, Mona, Kingston, Jamaica, West Indies, ${ }^{2}$ Department of Microbiology, Mount Sinai Hospital/University Health Network, Toronto, Ontario, Canada and ${ }^{3}$ Department of Laboratory Medicine and Pathobiology, University of Toronto, Toronto, Ontario, Canada.
Correspondence: Dr AM Nicholson, Department of Microbiology, The University of the West Indies, Mona, Kingston 7, Jamaica, West Indies. Email: alison.nicholson@uwimona.edu.jm 
Métodos: En el Laboratorio de Microbiología de un HAT en Jamaica, de mayo de 2009 a marzo de 2011, de 105 bacilos gram-negativos polifármacorresistentes aislados de especímenes clínicos presentados para identificación de rutina y pruebas de susceptibilidad, se seleccionaron todos los aislados de $\mathrm{P}$ aeruginosa (un total de 10) resistentes a MEM. Estos aislados fueron sometidos a prueba de detección de eflujo, usando el inhibidor de eflujo de fenilalaninaarginina- $\beta$-naftilamida (PAßN) en un método descrito por Giske et al en 2008.

Resultados: Este estudio detectó evidencia de eflujo de MEM en el $80 \%$ de P aeruginosa resistente a MEM implicado en infecciones nosocomiales en este HAT de Jamaica, usando el ensayo de inhibición PABN. Los aislados positivos al eflujo de meropenem pertenecían a dos linajes cromosómicos no relacionados.

Conclusión: Estos resultados subrayaron la necesidad de mejorar la vigilancia y el control para prevenir que este mecanismo vuelva a producirse en nuevas cepas de $\mathrm{P}$ aeruginosa.

Palabras clave: Eflujo, Pseudomonas, resistencia

West Indian Med J 2018; 67 (2): 106

\section{INTRODUCTION}

Pseudomonas $(P)$ aeruginosa may cause pulmonary, indwelling device, and skin and soft tissue infections (1, 2 ). As the most frequently isolated opportunistic pathogen from intensive care units (ICUs), it is also one of the leading causes of hospital-acquired infections globally and is associated with prolonged hospital stays (3).

Wild-type $P$ aeruginosa are intrinsically resistant to several antibiotics including the carbapenem, ertapenem, but they usually remain susceptible to treatment with the more potent carbapenem, meropenem [MEM] (4). As strains develop or acquire resistance to carbapenems, therapeutic options become limited, and the organism may cause serious morbidity as a healthcareassociated infection (5). Carbapenem resistance in $P$ aeruginosa may be as a result of numerous mechanisms, including drug inactivation via acquisition of class A or $\mathrm{B}$ carbapenemases or by mutational hyper-production of chromosomal ampC beta-lactamases, by penicillinbinding protein (PBP) target modification (PBP 5), by mutational reduction of permeability of the outer membrane porin protein $o p r D$ which facilitates carbapenem uptake and, finally, via drug efflux (4). While drug inactivation, target and permeability modifications are commonly acknowledged mechanisms of carbapenem resistance, active efflux is becoming increasingly recognized as a new major threat to the therapeutic use of these agents (6).

Pseudomonas aeruginosa isolates contain efflux pumps with the ability to specifically export MEM in preference to the other carbapenems as it has a chemically distinct side chain that facilitates its uptake (7,
8). These pumps, known as MexAB-OprM, MexCDOprJ and MexXY-OprM, confer resistance to MEM but not to other carbapenems (7-10). Detecting efflux as the cause of MEM resistance is important as, in such isolates, other carbapenems may still be utilized in therapy. Compounds such as phenylalanine-arginine- $\beta$ naphthylamide (PA $\beta \mathrm{N})$, also known as an efflux pump inhibitor (EPI), have been used to demonstrate the presence of active efflux (6). These inhibitors function by competing with MEM for active export by the efflux pump mechanism (3). This competitive action causes an elevation of intra-cellular MEM as the EPI is preferentially exported. This, in turn, restores antibacterial activity to MEM. Phenotypic tests designed to detect efflux mechanisms in MEM-resistant strains measure the EPI effect by comparing the MEM minimum inhibitory concentrations (MICs) with and without PA $\beta \mathrm{N}$, where a positive test is defined as one where a reduced MIC is noted in the presence of the EPI $(3,6)$.

During the period 2002 to 2004, a 33\% rate of resistance to several antibiotics, including MEM, was identified in $P$ aeruginosa isolates from infected patients in the ICU of a tertiary care hospital $(\mathrm{TCH})$ in Kingston, Jamaica (11). However, the mechanisms of carbapenem resistance in those isolates were not elucidated as would have been necessary to maximize antibiotic choice and guide practitioners in the implementation of the most appropriate infection control measures.

This study sought to determine whether efflux was a mechanism of resistance to MEM among more recent isolates of $P$ aeruginosa at the TCH using the PA $\beta \mathrm{N}$ 
inhibitor assay. Further, the relatedness of the isolates was established using pulsed field gel electrophoresis (PFGE) to determine if the strains had become endemic within the TCU.

\section{MATERIALS AND METHODS}

During the period May 2009 to March 2011, 10 MEMresistant $P$ aeruginosa isolates were noted among 105 multidrug-resistant (MDR) Gram-negative bacilli isolated during routine identification and susceptibility testing at the Microbiology Laboratory of the TCH. Isolates were recovered from de-duplicated clinical specimens that included six expectorated sputa, two urine samples, a single skin swab and an endotracheal tube tip. Meropenem efflux was suspected as isolates had proven to be polymerase chain reaction-negative when tested for common carbapenemases (data not shown). Active efflux was investigated using the inhibition assay described by Giske et al (12). In this method, the MEM MIC of each isolate was first determined using a bioMérieux Etest gradient strip. The efflux inhibition assay was then performed on MEM-resistant isolates by placing the MEM Etest strips onto Mueller Hinton agar, prepared in-house, that was supplemented with $40 \mathrm{mg}$ per litre of PA $\beta \mathrm{N}$. A reduction in MEM MIC by at least three doubling dilutions was considered as evidence of efflux activity. Typing of chromosomal DNA by PFGE using restriction enzymes Spe 1 and $X b a 1$ (Fermentas Life Sciences, United States of America) was performed on all 10 MEM-resistant $P$ aeruginosa isolates in order to determine strain relatedness.

\section{RESULTS}

Of the 10 MEM-resistant $P$ aeruginosa isolates studied, eight exhibited definite evidence of MEM efflux as they met or exceeded the criteria for a positive test (Table).

The Table summarizes the antibiogram, efflux and PFGE results of the $P$ aeruginosa isolates in the study.

Of these eight isolates, seven were from patients hospitalized in ICU-B, while the eighth was from a patient in the Dermatology ward. Pulsed field gel electrophoresis typing revealed two distinct lineages among the MEMefflux-positive $P$ aeruginosa isolates: Type 1 comprised five isolates and Type 2 comprised three isolates. While all isolates were highly related to each other within the two types (ie $>80 \%$ similarity; Figure), they were not indistinguishable.

Pulsed field gel electrophoresis demonstrated two distinct groups of highly related MEM-resistant $P$ aeruginosa, both of which had tested positive for active efflux of MEM in the phenotypic PA $\beta \mathrm{N}$ inhibitor assay. The high degree of relatedness within the study isolates indicated concurrent outbreaks or the possibility of two endemic strains.

The degree of variation present, although minor, was suggestive of endemic rather than epidemic spread. Regardless, it was suggested from these typing data that multiple strains capable of a carbapenem efflux were disseminating among patients within the ICU environment (Table). Further, these isolates were MDR. All the isolates with the exception of one that came from a urine sample of a patient admitted to the ICU were resistant to imipenem as well, suggesting that they may also be

Table: Source, susceptibility patterns, clonality and results of the efflux inhibition assay of meropenem-resistant Pseudomonas aeruginosa isolates

\begin{tabular}{|c|c|c|c|c|c|c|c|c|c|c|}
\hline \multirow[t]{2}{*}{$\begin{array}{c}\text { TCH } \\
\text { no. }\end{array}$} & \multirow[t]{2}{*}{ Specimen type } & \multirow[t]{2}{*}{$\begin{array}{l}\text { Patient } \\
\text { location }\end{array}$} & \multicolumn{6}{|c|}{$\begin{array}{l}\text { Antimicrobial susceptibility profile other than } \\
\text { MEM resistance }\end{array}$} & \multirow[t]{2}{*}{$\begin{array}{l}\text { MEM } \\
\text { efflux }\end{array}$} & \multirow[t]{2}{*}{$\begin{array}{c}\text { PFGE } \\
\text { type }\end{array}$} \\
\hline & & & $\mathrm{CN}$ & AK & CIP & CAZ & TZP & IMI & & \\
\hline 92 & Sputum & ICU-B & $\mathrm{R}$ & $\mathrm{S}$ & $\mathrm{R}$ & $\mathrm{R}$ & $\mathrm{R}$ & $\mathrm{R}$ & Yes & 1 \\
\hline 94 & Suctioned sputum & ICU-B & $\mathrm{R}$ & S & $\mathrm{R}$ & $\mathrm{R}$ & $\mathrm{R}$ & $\mathrm{R}$ & Yes & 1 \\
\hline 95 & Endotracheal tube tip & ICU-B & $\mathrm{R}$ & S & $\mathrm{R}$ & S & $\mathrm{R}$ & $\mathrm{R}$ & Yes & 1 \\
\hline 96 & Sputum & Private wing & $\mathrm{R}$ & S & $\mathrm{R}$ & $\mathrm{R}$ & $\mathrm{R}$ & $\mathrm{R}$ & No & 1 \\
\hline 109 & Suctioned sputum & ICU-B & $\mathrm{R}$ & S & NA & $\mathrm{S}$ & $\mathrm{R}$ & $\mathrm{R}$ & Yes & 1 \\
\hline 91 & Sputum & ICU-B & $\mathrm{R}$ & S & $\mathrm{R}$ & $\mathrm{R}$ & $\mathrm{R}$ & $\mathrm{R}$ & Yes & 2 \\
\hline 98 & Urine & ICU-B & $\mathrm{S}$ & $\mathrm{S}$ & $\mathrm{R}$ & $\mathrm{R}$ & $\mathrm{R}$ & $\mathrm{S}$ & Yes & 2 \\
\hline 102 & Sputum & ICU-B & $\mathrm{S}$ & S & NA & $\mathrm{R}$ & $\mathrm{R}$ & $\mathrm{R}$ & Yes & 2 \\
\hline 93 & Buttock swab & Dermatology & $\mathrm{R}$ & S & $\mathrm{R}$ & S & S & $\mathrm{R}$ & Yes & NA \\
\hline 97 & Urine & NA & $\mathrm{R}$ & $\mathrm{R}$ & $\mathrm{R}$ & $\mathrm{R}$ & $\mathrm{R}$ & $\mathrm{R}$ & No & NA \\
\hline
\end{tabular}

TCH: tertiary care hospital, MEM: meropenem, PFGE: pulsed field gel electrophoresis, CN: gentamicin, AK: amikacin, CIP: ciprofloxacin, CAZ: ceftazidime, TZP: piperacillin-tazobactam, IMI: imipenem, R: resistant, S: susceptible, NA: data not available. 


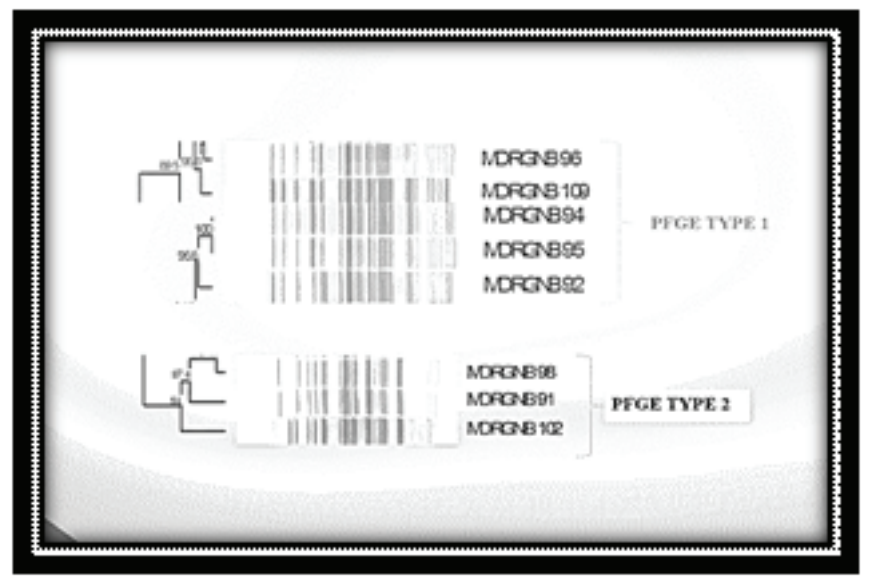

Figure: Results of pulsed field gel electrophoresis for Pseudomonas aeruginosa isolates in the study.

carrying other mechanisms of carbapenem resistance which need to be investigated.

\section{DISCUSSION}

Efflux appeared to be a mechanism of resistance among the majority of the MEM-resistant $P$ aeruginosa isolates in the sample. This had not been demonstrated previously in Jamaica. This finding may be very useful and could have potential implications regarding the suitability of the other carbapenems for clinical use $(7,8,10)$. If demonstrated to be susceptible, imipenem may be utilized successfully in treating infections caused by organisms capable of MEM-specific-efflux. Unfortunately, only one of these isolates was susceptible to imipenem which would have made it necessary for other therapeutic alternatives to be explored where treatment was indicated. All of the efflux-positive isolates belonged to two lineages within which all strains were highly related. This suggested that either multiple transient outbreaks were in progress at the time of sampling or that endemicity may have been established within the unit. The scope of the current study was too limited to answer this question. Since the majority of efflux isolates were from patients in the ICU, further surveillance studies would be advisable to determine whether these strains are in fact endemic and, if so, to locate and eliminate their environmental reservoirs such as within the plumbing and sinks $(13,14)$. Other surveillance studies have shown similar MDR organisms may be aerosolized from such sources to cause sporadic infections in patients within close proximity. Isolates that become endemic in a healthcare setting pose a risk of continuously infecting vulnerable patients over protracted periods resulting in increased morbidity and/or mortality.

\section{CONCLUSION}

An understanding of the prevalence and mechanism of carbapenem resistance in a local setting is important to drive infection prevention and control strategies and to formulate antibiotic policies to limit the emergence of further resistance and to ensure that appropriate therapy is initiated (15).

\section{ACKNOWLEDGEMENTS}

This project was supported by the Scotiabank Jamaica Foundation.

\section{AUTHORS' NOTE}

The opinions expressed by the authors do not necessarily reflect the opinions of Scotiabank Jamaica Foundation or the institutions with which the authors are affiliated. The study was approved by The University of the West Indies Ethics Committee.

\section{REFERENCES}

1. Murray PR, Pfaller MA, Rosenthal KS. Medical microbiology. Fifth edition. Philadelphia: Elsevier; Mosby; 2005.

2. Livermore D. Multiple mechanisms of antimicrobial resistance. Clin Infect Dis 2002; 34: 634-40.

3. Askoura M, Mattawa W, Abujamel T, Taher I. Efflux pump inhibitors (EPIs) as new antimicrobial agents against Pseudomonas aeruginosa. Libyan J Med 2011; 6: 5870.

4. Amin NE, Giske CG, Jalal S, Keijser B, Kronvall G, Wretlind B. Carbapenem resistance mechanisms in Pseudomonas aeruginosa: alterations of porin Opr D and efflux proteins do not fully explain resistance patterns observed in clinical isolates. APMIS 2005; 113: 187-96.

5. Queenan AM, Bush K. Carbapenemases: the versatile beta-lactamases. Clin Microbiol Rev 2007; 20: 440-58.

6. Renau T, Leger R, Flamme EM, Sangalang J, Lomovskaya O, Hecker $\mathrm{SJ}$ et al. Inhibitors of efflux pumps in Pseudomonas aeruginosa potentiate the activity of the fluoroquinolone antibacterial levofloxacin. J Med Chem 1999; 42: 4928-31.

7. Masuda N, Sakagawa E, Ohya S, Gotoh N, Tsujimoto H, Nishino T. Substrate specificities of MexAB-OprM, MexCD-OprJ, and MexXYOprM efflux pumps in Pseudomonas aeruginosa. Antimicrob Agents Chemother 2000; 44: 3322-7.

8. Okamoto K, Gotoh N, Nishino T. Extrusion of penem antibiotics by multicomponent efflux systems MexAB-OprM, MexCD-OprJ, and MexXY-OprM of Pseudomonas aeruginosa. Antimicrob Agents Chemother 2002; 46: 2696-9.

9. Poole K. Multidrug efflux pumps and antimicrobial resistance in Pseudomonas aeruginosa and related organisms. J Mol Microbiol Biotechnol 2001; 3: 255-64.

10. Quale J, Bratu S, Gupta J, Landman D. Interplay of efflux system, ampC, and oprD expression in carbapenem resistance of Pseudomonas aeruginosa clinical isolates. Antimicrob Agents Chemother 2006; 50: 1633-41.

11. Nicholson A, Ledgister S, Williams T, Robinson S, Gayle P, Lindo T et al. Distribution of nosocomial organisms and their resistance patterns in the Intensive Care Unit of the University Hospital of the West Indies, Kingston, Jamaica. West Indian Med J 2009; 48: 138-41. 
12. Giske CG, Buaro L, Sundsfjord A, Wretlind B. Alterations of porin, pumps, and penicillin-binding proteins in carbapenem resistant clinical isolates of Pseudomonas aeruginosa. Microb Drug Resist 2008; 14: 23-30.

13. Lowe C, Willey B, O'Shaughnessy A, Lee W, Lum M, Pike K et al. Outbreak of extended-spectrum $\beta$-lactamase-producing Klebsiella oxytoca infections associated with contaminated handwashing sinks. Emerg Infect Dis 2012; 18: 1242-7.

14. Ling ML, How KB. Pseudomonas aeruginosa outbreak linked to sink drainage design. Health Care Infection 2012; 18: 143.

15. Hawkey PM. The growing burden of antimicrobial resistance. J Antimicrob Chemother 2008; 62 (Suppl 1): i1-9. 